\title{
What constitutes healthy eating behaviour and lifestyle?
}

\author{
Dr Gerhard Jordaan is principal psychiatrist and lecturer in the Department of \\ Psychiatry, University of Stellenbosch. He is currently Head of Adult Psychiatry \\ at the Eating Disorder Unit at Tygerberg Hospital.
}

To what extent should doctors be concerned about the risks of abnormal eating behaviour? Having often asked medical students what they believe doctors should know about eating disorders I was recently pleased to hear a different answer to the ones usually offered. Students usually get it right with regard to making the correct diagnosis, ruling out medical causes for unexplained weight loss, and being able to manage medical and psychiatric complications. They may even suggest psycho-education, including dietary advice and cognitive behaviour psychotherapy. But this particular student's answer was the idealistic one that I personally tend to suggest at the end of a tutorial. Unfortunately, I believe its application may be elusive.

Most doctors, including psychiatrists, would consider obesity to be a concern, although not a psychiatric disorder. Weight gain has become a hot topic of discussion with the use of atypical antipsychotics.' We are also aware of the metabolic syndrome ${ }^{2}$ and its complications, including obesity, hypertension, diabetes, raised cholesterol, ischaemic heart disease and stroke. We may even have taken note of childhood obesity, which is currently described as an epidemic in Western societies such as the USA. ${ }^{3}$ It is interesting to consider the factors believed to contribute to this occurrence. Not only are children far less physically active than their ancestors, being more exposed to TV, video games and computers, they are also heavily exposed to TV commercials about food and soft drinks and increasingly less exposed to regular (healthy) meals prepared by mom. They do not even waste energy getting up to switch TV channels when the remote control is there on the couch, and similar convenience pertains at the local fast-food outlet's drivethrough facility! Not to comment on the availability of fresh fruit and veggies...

Society has probably instinctively responded to the awareness

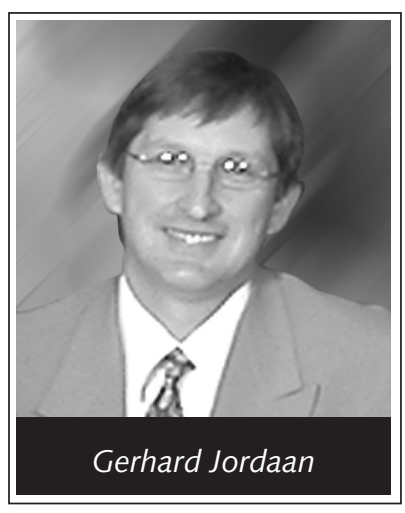

of the consequences of obesity. Consider that the cure for obesity lies, among other things, in promoting eating less. Remember the slogan: 'Gain health by losing weight'? But this does not apply to the patient with AIDS, tuberculosis or malignancy, or those susceptible to anorexia nervosa. Furthermore, is the concern about health, or is it primarily about appearance or perhaps performance?

Although we speculate about the aetiology of eating disorders, the ultimate cause remains an enigma. Psychosocial factors probably interact with biological vulnerability. In this respect men and women are not only socially different creatures, they are also biologically different. Il have yet to encounter a male person who craves chocolate on a monthly basis...l

To what extent can we counteract obesity without making our patients susceptible to eating disorders? Shouldn't the quest for autonomy and self-esteem, the perhaps undue emphasis on performance and physical appearance, the potential risks of perfectionistic, obsessive, ritualistic behaviour, and some recognition of the biological nature of both obesity and eating disorders be part of our awareness before we approach their prevention and management? 
I believe my student's answer was perfectly appropriate. He suggested that doctors should promote healthy eating behaviour and lifestyle, including exercise, to all their patients, irrespective of whether they suffer from eating disorders or not. His answer included a sense of commitment to all patients as well as a preventive approach. But then again, how do we promote healthy eating behaviour and lifestyle? How much emphasis on proper eating behaviour, weight loss, exercise, fitness, thinness and competitiveness is normal and can prevent eating disorders, especially in children?

As in many other disorders we can be probably strive to be preventive, provided we find the correct 'dosage' for each individual. But it would be interesting to know to what degree doctors agree on what really constitutes healthy eating behaviour and lifestyle...

\section{Gerhard Jordaan}

Department of Psychiatry

Stellenbosch University

1. McConville BJ, Sorter MT. Treatment challenges and safety considerations for antipsychotic use in children and adolescents with psychoses. J Clin Psychiatry 2004 65: Suppl 6, 20-29.

2. International Obesity Task Force. The obesity epidemic, metabolic syndrome and future prevention strategies. Eur J Cardiovasc Prev Rehabil 2004; 11 (1): 3-8.

3. Ebbeling CB, Pawlak DB, Ludwig DS. Childhood obesity: public-health crisis, common sense cure. Lancet 2002; 360: 473-482. 